Reference Communities: Applying the Community of Practice Concept to Development of Reference Knowledge

Robin E. Miller

University of Wisconsin-Eau Claire

Author Note

Robin Miller, McIntyre Library, University of Wisconsin, Eau Claire.

Correspondence concerning this article should be addressed to Robin Miller, 1001C McIntyre Library, University of Wisconsin-Eau Claire, Eau Claire, WI 54702-4004. E-mail: millerob@uwec.edu

Author Posting. (c) Taylor \& Francis Group, LLC, 2011. This is the author's version of the work. It is posted here by permission of Taylor \& Francis Group, LLC for personal use, not for redistribution. The definitive version was published in Public Services Quarterly, Volume 7, Issue 1, June 2011.

doi:10.1080/15228959.2011.572772

(http://dx.doi.org/10.1080/15228959.2011.572772) 


\begin{abstract}
Communities of practice offer reference librarians a conceptual model through which to develop and maintain general and subject specific knowledge. Reference librarians acquire general and subject-specific knowledge in many ways, sometimes independently and sometimes collaboratively. Applying the concept of the "community of practice" to reference librarians may inform understanding of how librarians can work together to build knowledge and develop professionally.
\end{abstract}

Keywords community of practice, reference knowledge, reference librarian, reference service 
Reference Communities: Applying the Community of Practice Concept to Development of

\section{Reference Knowledge}

Reference librarians, whether generalists or subject-specialists, rely on continually evolving expertise. In every reference transaction, librarians summon knowledge of disciplines and subjects, search tools, and the foundations of library science education. Disciplinary knowledge grows through formal and informal learning experiences, while the form, function, and relevance of the tools available to locate information evolve. Many academic librarians have dual roles as both generalists and subject specialists, working with patrons at public service points, through research consultations, and in other contexts. Reference librarians who wear both generalist and specialist hats might seem to have the impossible task of keeping up. These librarians must maintain sufficient general expertise to adequately respond to a wide range of questions while also developing a “deep but broad” (Rodwell, 2001) command of a subject or subjects. Librarians have many opportunities to develop reference expertise, through formal professional development classes or academic course-work, and informally, by staying up-todate with relevant publications. On the quest to maintain reference expertise, reference librarians should examine how they exchange information with their colleagues. Forming collegial learning communities may help reference librarians to build sufficient knowledge and shift easily between generalist and specialist identities.

This article was prompted by a new academic librarian’s experience assuming a multifaceted role in the reference department of an academic library. The objective of this article is to explore how "keeping up” can be conceived of as a collective endeavor and not solely as an independent obligation. This article first examines strategies for maintaining reference expertise. Second, the article examines the theoretical framework of the "community of practice," as 
introduced by organizational theorists like Jean Lave and Etienne Wenger, and how reference librarians may apply it to building reference knowledge. By integrating conventional approaches to "becoming a renaissance reference librarian" (Smith \& Oliva, 2009) into a localized community of practice, reference librarians can help their colleagues develop general or subjectspecific expertise. The concept of the community of practice offers a model for a group of colleagues who wish to support the growth and development of each other's general, disciplinary, or interdisciplinary knowledge.

\section{Building Reference Knowledge}

In the literature about generalist and subject specialist expertise, several authors have discussed practical approaches to building reference knowledge. While academic librarians have varying attitudes about the necessity for an advanced degree in providing quality reference service (Mayer \& Terrill, 2005), the roles of subject specialists have particularly changed at small- and medium-sized academic libraries where new service models have altered library operations (McAbee \& Graham, 2005). New roles may require a continuous effort to build knowledge and expertise. Hill (2001) argues that the most successful reference librarians should have a "very broad base of subject knowledge ... made up not only of the specialized knowledge of a given discipline, but also knowledge of the world at large” (p. 223). To obtain this knowledge, Hill offers practical suggestions like following current events, visiting museums and watching educational television, meeting with teaching faculty, taking classes, and attending seminars or talks. These independent activities also emerge in Smith and Oliva's (2010) outline of four strategies used by librarians to build and maintain reference knowledge: self-directed education; informal collegial training; formal/in-house training; and formal/outside training. 
Many librarians chafe against the bookworm stereotype, but reading is a common theme in the literature about “keeping up.” Dilevko and Gottlieb (2004) put forth a book-length argument that librarians should make more time to read "everything and anything, from biographies about historical figures to local and national newspapers to general-interest magazines to best-selling novels” (p. 6). Others have suggested reading or browsing a wide variety of publications (Hill, 2001; Knapp, 2010; Smith \& Oliva, 2009), including newspapers, magazines of general interest like the New Yorker and Wired, book reviews, core research journals in a discipline, and reference works. For librarians who read widely online, RSS feeds and social bookmarking are readily available tools for following blogs and news Web sites, not to mention new book reviews and tables of contents from relevant journals (Farkas, 2007).

Reading certainly offers librarians a flexible opportunity to build knowledge at their own pace. However, Knapp (2010) argues that librarians should exchange information and engage in wide ranging discussion with colleagues because there is a social dimension to developing interdisciplinary knowledge. The informal collegial training opportunities discussed by Smith and Oliva suggest that reference librarians value opportunities to share and exchange knowledge with their colleagues. Auster and Chan (2004) explore organizational support for professional development that enables librarians to stay up-to-date, finding that librarians who work in libraries with a strong "updating climate” (p. 61) are accustomed to a high level of information sharing between colleagues. They hypothesize that librarians who work in an "updating climate" share more information between colleagues, diminishing the extent to which they consciously seek informal professional development opportunities.

Reference librarians clearly have many opportunities to develop general and subjectspecific expertise. Given limited time, these opportunities may be viewed as a menu from which 
a reference librarian might select, depending on time, resources and an identified learning goal. Understanding Knapp’s suggestion that there is a social dimension to developing expertise, a worthy area of exploration might be how reference librarians learn from each other to build general or subject-specific knowledge.

\section{Understanding the Community of Practice}

The community of practice is an alternate view of developing general or subject specific reference expertise. The theoretical underpinnings of the community of practice were introduced by Lave and Wenger (1991) as a way to understand learning, particularly learning situated in the workplace. The elements of the community of practice are described succinctly by Wenger, McDermott and Snyder:

A community of practice is a unique combination of three fundamental elements: a domain of knowledge, which defines a set of issues; a community of people who care about this domain; and the shared practice that they are developing to be effective in their domain. (2002, p. 27)

Although the community of practice has been interpreted and applied in numerous theoretical and practical contexts (Cox, 2005), the three elements described by Wenger et al. form a “knowledge structure” in which practitioners “develop and share knowledge” (2002, p. 29).

Communities of practice may arise organically, without the participants knowing or acknowledging their participation. Alternatively, an organization or group of co-workers can form an ad hoc or long-standing community of practice. Using the example of claims processors in the insurance industry, Wenger et al. suggest that communities of practice emerge when groups seek to “address recurring sets of problems together” (2002, p. 26). 
The literature about communities of practice has focused largely on business and, to a lesser extent on higher education. Claims processors, a classic example in the community of practice literature, are analogous to reference librarians, who take in and respond to a continuous flow of information. Indeed, a group of reference librarians in a library are likely to possess each of the characteristics outlined by Wenger et al. Reference librarians belong to a community with shared practice and distinct domain of knowledge. Forming a community of practice could support development and exchange of generalist and subject specialist expertise, not to mention other professional development, transitions to new service models, and maintenance of institutional memory. Forming a community of practice can enable reference librarians to apply their expertise and to construct knowledge by collaborating with colleagues to solve problems posed by reference queries. Indeed, many reference departments are probably actively engaged in a community of practice, whether or not they have applied that terminology.

\section{Communities of Practice in Libraries}

\section{Welcoming the Newcomer}

Central to Wenger and Lave's notion of community of practice is the problem of how “newcomers” learn from “old-timers.” Generalists and subject specialists often find themselves in the position of newcomer to information sources, tools, and strategies for discovery. While our patrons may perceive us as being old-timers when it comes to the resources and tools we teach them to use, the newcomer - old-timer dynamic also emerges between librarians. For example, new employees of a library might be characterized as newcomers to the resources, tools, and practices of a particular library. As a new academic librarian, I joined the McIntyre Library at the University of Wisconsin-Eau Claire, where I provide both general and government documents reference at a combined service point. This is a multi-faceted role that also includes liaison and 
collection development responsibilities in several areas. As I took on a new role at an unfamiliar institution, consulting with my colleagues became paramount. I found that my colleagues (oldtimers) had a well-established community of practice that supported a situated learning process in which I (a newcomer) learned on the job. Within this community, I became knowledgeable about the library’s resources and tools, acclimated to localized institutional practices, and gained experience solving problems common to our patrons.

A community of practice facilitates the newcomer's development of knowledge and expertise. By participating in a community of practice, newcomers gain experience with the “activities, identities, artifacts, and communities of knowledge and practice” (Lave \& Wenger, 1991, p. 29) that characterize a given group of professionals. Through our community of practice, my colleagues transferred some liaison responsibilities to me; instead of becoming the “accidental” American Indian Studies Liaison, my colleagues provided cross training about tools and resources and we openly discussed many aspects of the subject as I gained experience working with patrons in this discipline. Although I independently built expertise about this field through reading, attending workshops, and talking with faculty, the community of practice has supported the growth and application of my knowledge.

Lave, Wenger, and other theorists of the community of practice do not assign a specific structure to the concept. In other words, a community of practice does not have defined characteristics like a weekly meeting, an e-mail listserv, or regular conference calls. Any of these characteristics may be a feature of a community of practice, but no feature is definitive. The formal aspects of the McIntyre Library’s community of practice include a semi-monthly meeting of the librarians and staff who compose the Research and Instruction Department; this meeting is a forum for departmental business, but also for training and problem solving. Informal features 
of our community of practice include cross training at the reference desk, which helped me to build general knowledge about the library and questions common to our patrons. Cross training was also an opportunity for a colleague to share expertise about subject-specific resources and strategies for responding to common research assignments that drive patrons to the library. For example, when a steady stream of psychology students approached the reference desk in search of a "meta-analysis," I was prepared because my colleagues and I had discussed strategies for responding to this very assignment. Our community of practice relies on several collaboratively developed tools, including a database of reference questions, an annually updated departmental manual, and a blog for communicating with student employees.

Reference librarians who form a community of practice may be "newcomers” and “oldtimers” simultaneously. The newcomer - old-timer dynamic is particularly applicable to librarians who serve dual roles as both generalists and subject-specialists. At any given time, reference librarians may be teaching and learning from their colleagues. As the government documents librarian at my institution, I have used meetings, cross-training opportunities, and tutorials to orient my colleagues to strategies for accessing legislative and regulatory information. Database training is a frequent feature of our semi-monthly department meetings. These trainings have offered the business subject specialist an opportunity to train all the reference librarians to assist patrons with popular but difficult-to-use resources like Simmons Choices and MRI+. Training can also be delivered through printed or Web-based materials. A growing leisure reading collection at our institution prompted the education subject specialist to develop a Web-based guide to reader's advisory, featuring strategies, tools, and resources for making book recommendations to adult readers. In each of these examples, newcomers learned from old-timers. These examples of a community of practice in action align with Smith and 
Oliva’s discussion of the "renaissance reference librarian," where communication, mediation, and exchange of information emerge in either formal or informal in-house training.

Communities of practice may also foster the development of tools and infrastructure that support training. Many libraries have implemented social software tools to manage and exchange information (Farkas, 2007). Rodriguez (2010) examines implementation of blogs for internal communication among reference librarians at two academic libraries, finding that internal blogs play a compelling role in building knowledge of institutional practices and procedures. In addition to blogs, other Web 2.0 tools, like wikis, shared calendars, online photo collections, and social bookmarks can be effective for coordinating communication between reference managers and librarians, staff, and student employees (Currie, 2010). These tools offer opportunities to share operational announcements, "how-to” guides for a resource or technology, and even information about a particular subject or resource. Internal databases are another option for sharing reference expertise and "knowledge that is difficult to characterize, although reference librarians will frequently get questions related to this material” (Jantz, 2001, p. 36). In the examples offered by Rodriguez, Currie, and Jantz, archived posts form a shared knowledge base, an enduring characteristic of a community of practice.

\section{Active Engagement}

An essential element of the community of practice is that each participant is actively involved in the community and its core activity. In building the "knowledge structure" at the core of a community of practice, reference librarians communicate general or subject knowledge, mediate unfamiliar concepts or content, discuss or apply knowledge, and even build infrastructure for sharing knowledge. 
Although not characterized as a "community of practice," a collaborative service model described by Darby, Northrup, Waddell, and Watters (2004) offers an excellent example of learning situated within active practice. In this anecdote about cooperative reference at Samford University, reference librarians serve patrons while building each other's professional knowledge about reference resources, instruction, interlibrary loan and government documents. These librarians have fostered situated learning opportunities in which a librarian with expertise in an area may coach another through answering a question. Multiple librarians may contribute a response to an email or telephone reference question. Following up on reference questions with colleagues, sharing written responses to patron questions, and a keeping a log to track questions and answers enables these librarians to learn from each other on the job (Darby et al., 2004).

Darby et al. describe additional cooperative strategies. Subject specialists develop guides and pathfinders that help anyone working at the reference desk to become familiar with core resources in a field, diminishing the need to refer a patron to a subject specialist. Formal and information training opportunities are also valued. Darby et al. describe sharing the learning outcomes of training opportunities with each other, so that more than one person gains from participation in a professional development activity. To ensure that any librarian or staff member can respond to most government documents questions without the need for a referral, the entire reference department received training about government documents from the subject specialists in that area (Darby et al., 2004). The Samford example typifies the transformative nature of Lave and Wenger's community of practice concept. By capitalizing on situated learning opportunities and building each participant’s “knowledgeability” (Lave and Wenger, 1991), the Samford librarians altered their practice as librarians and their operations as a reference organization. 
While every librarian’s situation will differ, small and medium-sized academic libraries routinely ask librarians to fill dual roles (McAbee \& Graham, 2005), responding to both general and subject-specific reference queries. Generalists and subject specialists have opportunities to learn from each other through observation, discussion, and immediate application of new knowledge in reference environments. A reference department in which each librarian controls reference to specific subjects is a "distributed" community in which information sharing is not expected. New service models, including liaison programs, embedded librarianship, roving reference, and combined service points have altered the reference landscape for many librarians, inevitably breaking down silos of knowledge. Further, the growth of interdisciplinary programs at many institutions may inspire some to expand their expertise in particular subject areas.

A community of practice enables librarians to cultivate knowledge of the major concepts, methods, tools, and vocabulary common to different subject areas. Turning to a colleague and saying, "I'm struggling to find literature that applies this theory. Tell me how you would approach this," is an example of using a community of practice to build and apply knowledge. A community of practice could rely upon any combination of collaborative tools like wikis, blogs, or internal databases; regular lunchtime discussions of current events or the latest research published in a field; or cross-training meetings in which everyone reviews a new database interface or learns about finding standards and patents. In essence, communities of practice enable participants to define the learning opportunities and structures for building knowledge that are effective for the group and individual members.

\section{Conclusion}

Communities of practice support the intentional growth of knowledge. Librarians have well-established practices and habits for building and maintaining general and subject-area 
expertise; however, the community of practice offers librarians a way to conceive of building reference knowledge that is both cooperative and flexible. Forming a community of practice offers reference librarians situated learning opportunities in which new knowledge is built through application. Through a community of practice, reference librarians can commit to ongoing curiosity, exploration, and information sharing through formal and informal interactions. Further, the concept of the community of practice allows reference librarians to view the development of expertise as a collective effort.

Generalist and specialist librarians, and librarians whose roles and subject-area assignments are changing, are likely to draw on many sources to acquire and maintain expertise. For small and medium-sized academic libraries, and for any library that lacks the resources to employ a large number of subject specialists, the community of practice offers a practical model in which librarians can maintain expertise in areas of patron interest. The community of practice is a promising concept for reference librarians who navigate between broad and narrow subject areas, articulating a form for the knowledge structures that librarians can build to support collegial learning and development. 


\section{References}

Auster, E., \& Chan, D. C. (2004). Reference librarians and keeping up-to-date. Reference \& User Services Quarterly, 44(1), 57-66.

Cox, A. (2005). What are communities of practice? A comparative review of four seminal works. Journal of Information Science, 31, 527-540.

Currie, J. P. (2010). Web 2.0 for reference services staff training and communication. Reference Services Review, 38(1), 152-157.

Darby, D. H., Northrup, L. A., Waddell, C. T., Watters, H. F. (2004). Cooperation in a multifaceted reference department: Blending resources, personnel, and services of reference, instruction, interlibrary loan, and government documents. The Reference Librarian, 40(83/84), 119-130.

Dilevko, J., \& Gottlieb, L. (2004). Reading and the reference librarian: The importance to library service of staff reading habits. Jefferson, NC: McFarland \& Company.

Farkas, M. G. (2007). Social software in libraries. Medford, NJ: Information Today.

Hill, K. C. (2001). Acquiring subject knowledge to provide quality reference service. The Reference Librarian, 34(72), 219-228.

Jantz, R. (2001). Knowledge management in academic libraries: special tools and processes to support information professionals. Reference Services Review, 29(1), 33-39.

Knapp, J. A. (2010). Walls tumbling down: Opportunities for librarians in interdisciplinary research. In S. W. Witt \& L. M. Rudasill (Eds.), Social science libraries: Interdisciplinary collections, services, networks (pp. 53-61). The Hague, The Netherlands: International Federation of Library Association and Institutions. 
Lave, J., \& Wenger, E. (1991). Situated learning: Legitimate peripheral participation. Cambridge, England: Cambridge University Press.

Mayer, J., \& Terrill, L. J. (2005). Academic librarians’ attitudes about advanced-subject degrees. College \& Research Libraries, 66(1), 59-73.

McAbee, S. L., \& Graham, J. (2005). Expectations, realities, and perceptions of subject specialist librarians’ duties in medium-sized academic libraries. Journal of Academic Librarianship, 31(1), 19-28.

Rodriguez, J. (2010). Social software in academic libraries for internal communication and knowledge management: A comparison of two reference blog implementations. Internet Reference Services Quarterly, 15(2), 107-124.

Rodwell, J. (2001). Dinosaur or dynamo? The future for the subject specialist reference librarian. New Library World, 102(1160/1161), 48-52.

Smith, D. A., \& Oliva, V. T. (2010). Becoming a renaissance reference librarian in academe: Attitudes toward generalist and subject specific reference and related profession development. Reference Services Review, 38(1), 125-151.

Wenger, E., McDermott, R. A., \& Snyder, W. (2002). Cultivating communities of practice: A guide to managing knowledge. Boston, MA: Harvard Business School Press. 